\title{
The Effectiveness of Problem Posing Approach in Term of Mathematical Thinking Skill
}

Ahmad Nasrullah ${ }^{1 *}$

* Affiliasi: Universitas Islam Negeri Mataram

\section{Keywords:}

Effectiveness, problem

posing, mathematical

thinking skill.

\section{Kata kunci:}

Efektifitas, pendekatan problem posing, kemampuan berpikir matematis siswa.

\begin{abstract}
A b s t r a c t: This study aims to describe the effectiveness of problem posing approach in term of mathematical thinking skill of senior high school students. This study was a quasi-experimental study using the nonequivalent pretest and posttest group design. The population was year X students of State Senior High School 1 of Sakra Lombok Timur that consisted of six classes. The sample was two classes selected randomly from all Year X classes; class X-5 received a treatment of problem posing approach and class X-6 received as a control class. The instrument used is a test to measure mathematical thinking skill. To find out the effectiveness of problem posing approaches in the mathematical thinking skill, the data were analyzed using One Sample Test. The result of the study states that problem posing approach is effective in terms of the mathematical thinking skill of Senior High School Students.
\end{abstract}

A b s t $\mathbf{r}$ a k: Penelitian ini bertujuan untuk mengetahui keefektifan pembelajaran problem posing ditinjau dari kemampuan berpikir matematis siswa sekolah menengah atas. Penelitian ini adalah penelitian eksperimen semu dengan menggunakan desain nonequivalent pretest-posttest group. Populasi penelitian ini adalah semua siswa kelas X SMAN 1 Sakra Lombok Timur yang terdiri dari 6 kelas. Sedangkan sampelnya dua kelas yang diambil secara acak dari semua kelas $\mathrm{X}$ dan didapatkan kelas X-5 terpilih sebagai kelas dengan pembelajaran menggunakan pendekatan problem posing dan kelas X-6 terpilih sebagai kelas control. Instrumen yang digunkan adalah tes untuk mengetahui kemampuan berpikir matematis siswa. Untuk mengetahui keefektifan pendekatan problem posing ditinjau dari kemampuan berpikir matematis siswa, data dianalisisi dengan menggunakan one sample test. Hasil dari

\footnotetext{
${ }^{1}$ Coresponden to author: Prodi Tadris Matematika, Fakultas Tarbiyah dan Keguruan, Universitas Islam Negeri Mataram, Jl. Gajah Mada Jempong, Indonesia. (83116), e-mail addresses: ahmadnasrullah@uinmataram.ac.id
}

Ahmad Nasrullah (2021), The Effectiveness of Problem Posing Approach..... 
penelitian ini mengatakan bahwa pendekatan problem posing efeketif ditinjau dari kemampuan berpikir matematis siswa.

\section{Article info}

Article History: Received 20 Agustus 2021|Revised 30 Agustus 2021|Accepted 13 September 2021| Available online 20 September 2021

\section{Pendahuluan}

Dalam peraturan Menteri Pendidikan Nasional (Permendiknas) No 22 Tahun 2006 tentang standard isi, disebutkan bahwa mata pelajaran matematika di tingkat Sekolah Menengah Atas (SMA) bertujuan agar peserta didik memiliki kemampuan sebagai berikut; (1) memahami konsep matematika, menjelaskan keterkaitan antarkonsep dan mengaplikasikan konsep atau algoritma secara luwes, akurat, efisien, dan tepat, dalam pemecahan masalah; (2) menggunakan penalaran pada pola dan sifat, melakukan manupilasi, matematika dalam membuat generalisasi, menyusun bukti, atau menjelaskan gagasan dan pernyataan matematika; (3) memecahkan masalah yang meliputi kemampuan memahami masalah, merancang model matematika, menyelesaiakan model dan menafsirkan solusi yang diperoleh; (4) mengomunikasikan gagasan dengan symbol, tabel, diagram, atau media lain untuk memperjelas keadaan atau masalah; dan (5) memiliki sikap menghargai kegunaan matematika dalam kehidupan, yaitu memiliki rasa ingin tahu, perhatian, dan minat dalam mempelajari matematika, serta sikap ulet dan percaya diri dalam pemecahan masalah.

Berdasarkan uraian di atas maka dapat dismpulkan bahwa tujuan matematika sekolah khsusunya matematika di tingkat SMA adalah untuk mengembangkan kemampuan berpikir. Hal ini sejalan dengan pendapat Marsigit (2007: 12) yang menyatakan bahwa tujuan kurikulum matematika di Indonesia adalah untuk mengembangkan kemampuan berpikir. Bahkan mengembangkan kemampuan berpikir ini mulai disadari akan pentingnya dan dimasukkan ke dalam kurikulum di berbagai negara di dunia (Khalid, 2007: 169).

Paul Suparno (1997: 65) menjelaskan bahwa memiliki kemampuan berpikir lebih baik dari pada sekedar menjawab dengan benar. Seorang anak yang mampu menjawab benar pada suatu soal belum tentu bisa menjawab dengan benar untuk soal yang berbeda. Namun seorang anak yang mempunyai kemampuan berpikir yang bagus maka dipercaya akan mampu menyelesaikan soal dalam setiap kondisi yang baru. Stacey (2007:39) juga menjelaskan berpikir matematis sangat penting untuk tiga hal, yaitu: (1) berpikir matematis merupakan tujuan penting dari sekolah, (2) berpikir matematis merupakan hal penting untuk belajar matematika, dan (3) berpikir matematis merupakan hal penting untuk mengajar matematika.

Berpikir matematis juga merupakan metode matematis dalam berpikir yang digunakan untuk menyelesaikan masalah dalamkehidupan sehari-hari termasuk di sekolah (Khalid, 2007:

Ahmad Nasrullah (2021), The Effectiveness of Problem Posing Approach..... 
169). Lebih lanjut dijelakan bahwa berpikir matematis adalah mengaplikasikan teknis matematis, konsep dan proses secara implisit dan eksplisit dalam menyelesaikan masalah.

Katagiri (2007: 116) mengatakan bahwa kemampuan berpikir matematis adalah kemampuan seseorang ketika menghadapi suatu masalah untuk memustuskan atau memilih perangkat psikologis mana yang akan digunakannya untuk menyelesaikan masalah tersebut. Lebih lanjut ia menjelaskan bahwa berpikir matematis dapat dibagi menjadi tiga kategori, yaitu berpikir matematis terkait metode matematis, berpikir matematis terkait sikap matematis, dan berpikir matematis terkait konten/isi matematis. Dalam penelitian ini fokus pada berpikir matematis terkait metode matematis.

Berpikir matematis yang terkait dengan metode matematis menurut Katagiri (2007: 117) terdiri dari berpikir induktif, berpikir analogis, berpikir deduktif, berpikir integrative, berpikir mengembang, berpikir abstrak (abstraksi, konkretisasi, idealisasi, dan klarifikasi keadaan), berpikir simple (simplikasi), berpikir generaliser (generalisasi), berpikir mengkhususkan (spesialisasi), berpikir dengan simbil (simbolisasi), dan berpikir yang diungkapkan dengan bilangan kuantitas serta gambar.

Berdasarkan hasil observasi dan wawancara dengan guru matematika SMAN 1 Sakra Kabupaten Lombok Timur NTB, sebagian besar pembelajaran matematika masih berpusat pada guru (teacher center learning). Hal ini berakibat pembelajaran masaih bersifat monoton yang menyebabkan rendahnya sikap dan minat belajar siswa. Siswa juga mengalami kesulitan ketika menjawab soal yang tidak sama persisi dengan contoh soal yang diberikan. Kebiasaan mereka diberikan soal-soal yang sifatnya tertutup membuat mereka kurang kreatif dalam menyelesaiakn soal yang diberikan.

Rendahnya mutu pembelajaran di SMAN 1 Sakra secara khusus dan rendahnya mutu pendidikan di Indonesia secara umum terutama bidang matematika tidak lepas dari kualitas pembelajaran di dalam kelas. Untuk meningkatkan kualitas pembelajaran di dalam kelas, guru dituntut untuk mencari inovasi-inovasi pembelajaran sehingga mampu meningkatkan kualitas pembelajaran terutama dalam rangka meningkatkan kemampuan berpikir siswa. Salah satu pendekatan pembelajaran yang bisa meningkatkan dan mengembangkan kemampuan berpikir siswa adalah dengan pendekatan problem posing (Suparno: 2002; Silver :1997; Marsigit: 2009). Bahkan dikatakan problem posing ini sebagai inti pembelajaran matematika (Christou et al: 2005). Problem posing juga diklaim bisa memotivasi siswa berpikir kritis sekaligus dialogis, kreatif, dan interaktif (Suryosubroto, 2009: 203). Hal serupa juga dikatakan oleh Johnson (2007: 215) yang mengatakan bahwa problem posing merupakan bagian penting dari berpikir kreatif dan berpikir terbuka.

Berdasarkan latar belakang di atas, penelitian ini bertujuan untuk mendeskripsikan dan membandingkan keefektifan pembelajaran dengan pendekatan problem posing dan pendekatan konvensional ditinjau dari kemampuan berpikir matematis siswa.

Ahmad Nasrullah (2021), The Effectiveness of Problem Posing Approach.....

Vol. 01. No. 02, 2021 | h. 136 


\section{Metode}

Penelitian ini menggunakan metode quasiexperiment (eksperimen semu), yaitu menggunakan kelompok yang sudah terbentuk secara alami dan tidak bebas memilih individu dalam kelompok yang sudah terbentuk itu (Creswell, 2013: 242). Sedangkan rancangan penelitian menggunakan pretes-postes with non-equivalent group design yang secara skematis dapat digambarkan sebagai berikut.

\begin{tabular}{lll} 
Kelompok E & $\mathrm{T}_{1}$----- $\mathrm{X}_{1}$---- $\mathrm{T}_{2}$ \\
\hline Kelompok K & $\mathrm{T}_{1}$----- $\mathrm{X}_{2}$----- $\mathrm{T}_{2}$
\end{tabular}

Gamabr 1. Pretest-posttest non-equivalent group design
Keterangan
$\mathrm{T}_{1}$ : pretest kelas eksperimen dan kelas kontrol
$\mathrm{T}_{2}$ : posttest kelas eksperimen dan kelas kontrol
$\mathrm{X}_{1}$ : kelas dengan perlakuan pembelajaran problem posing
$\mathrm{X}_{1}$ : kelas dengan tanpa pembelajaran problem posing

Penelitian ini dilakukan di SMA Negeri 1 Sakra Lombok Timur NTB yang belangsung bulan Oktober 2020. Populasi penelitian ini adalah seluruh siswa kelas X SMA 1 Sakra Tahun Pelajaran 2020/2021 yang terdiri dari 6 kelas. Sampel dalam penelitian ini siswa dari dua kelas yang terpilih dari 6 kelas yang ada. Setalah dilakukan pengundian didapatkan kelas X-5 sebagai kelas eksperimen dan kelas X-6 sebagai kelas control.

Variabel dalam penelitian ini terdiri dari dua jenis yaitu variable bebas berupa pendekatan pembelajaran problem posing dan variable terikat berupa kemampuan berpikir matematis. Sedangkan pengumpulan data dalam penelitian ini dilakukan dengan menggunakan tes tertulis bentuk uraian. Tes ini diberikan dua kali yaitu tes awal (pretest) yaitu tes yang diberikan sebelum dilakukan pembelajaran dan tes akhir (postest) yaitu tes yang diberikan setelah selesai pembelajaran.

Sebelum digunakan untuk mengumpulkan data, instrumen penelitian berupa tes terlebih dahulu divalidasi oleh ahli kesesuaian isi dengan kurikulum yang digunakan. Hasilnya instrument dinyatakan valid dengan beberapa perbaikan. Selanjutnya dilakukan uji reliabilitas instrumen yaitu dengan mencari nilai indeks reliabilitas dengan menggunakan rumus Alpha Cronbach (Ebel \& Frisbie, 1986: 79) berikut.

$$
r=\frac{k}{k-1}\left[1-\frac{\sum S_{i}^{2}}{S_{t}^{2}}\right]
$$

Ahmad Nasrullah (2021), The Effectiveness of Problem Posing Approach..... 
Keterangan:

$r=$ koefien reliabilitas

$k=$ jumlah butir soal

$\sum S_{i}^{2}=$ jumlah varian skor tiap-tiap butir tes

$S_{t}^{2}=$ varian skor total

Hasil perhitungan koefesien reliabilitas diperoleh nilai Alpha Cronbach 0,829. Data kemampuan berpikir matematis siswa diperoleh melalui pengukuran dengan instrument tes yang berbentuk uraian. Skor yang dipeoleh dikonversi menjadi nilai dengan rentang 0 hingga 100.

Data yang diperoleh selanjutnya dianalisis dengan menggunakan one sample t-test dengan menggunakan program SPSS 20.0 for windows. Analisis one sample t-test ini digunakan untuk mengetahui keefektifan pendekatan pembelajaran problem posing ditinjau dari kemampuan berpikir matematis siswa SMA. Data yang digunakan adalah data yang diperoleh dari posttest setelah dilakuka treatment. Secara umum hipotesis statistic yang diuji sebagai berikut.

$H_{0}: \mu \leq \mu_{0}, \quad H_{a}: \mu>\mu_{0}$ dengan taraf signifikansi $\alpha=0.05$

Statistik one sample t-test dirumuskan dengan $t=\frac{\bar{x}-\mu_{0}}{s \sqrt{n}}$

Keterangan::

$\bar{x}$ : rata-rata sampel

$\mu_{0}$ : rata-rata yang ditetapkan

$\mathrm{s}$ : varian sampel

$\mathrm{n}$ : Banyaknya anggota sampel

Keriteria keputusan yaitu tolak $\mathrm{H}_{0}$ jika $\mathrm{t}_{\text {hitung }}>\mathrm{t}_{\text {tabel }}$

\section{Hasil dan Pembahasan}

\section{Analisis Data}

Secara ringkas, hasil tes kemampuan berpikir matematis siswa sebelum diberikan perlakuan dapat disajikan sebagai berikut.

Tabel 2. Data Pretest Kelas Eksperimen dan Kelas Kontrol

\begin{tabular}{lcc}
\hline \multicolumn{1}{c}{ Deskripsi } & Kelas Eksperimen & Kelas Kontrol \\
\hline Rata-rata & 42,48 & 41,99 \\
Standar deviasi & 9,39 & 9,74 \\
Nilai maksimum & 61 & 69 \\
Nilai minimum & 28 & 25 \\
\hline
\end{tabular}

Ahmad Nasrullah (2021), The Effectiveness of Problem Posing Approach..... 
Sebelum data pretest dianalisis, terlebih dahulu dilakukan uji normalitas dan uji homogenitas.

Tabel 3. Data Posttest Kelas Eksperimen dan Kelas Kontrol

\begin{tabular}{lcc}
\hline \multicolumn{1}{c}{ Deskripsi } & Kelas Eksperimen & Kelas Kontrol \\
\hline Rata-rata & 85,48 & 73,99 \\
Standar deviasi & 9,39 & 9,74 \\
Nilai maksimum & 97 & 86 \\
Nilai minimum & 70 & 68 \\
\hline
\end{tabular}

Sebelum dilakukan uji hipotesis, terlebih dahulu dilakukan uji prasyarat yang mencakup uji normalitas dan uji homogenitas. Hasil uji normalitas pada data univariat dapat dilihat dari hasil signifikansi Kolmogorov-smirnov dengan menggunakan bantuan software SPSS 20.0 for windows. Berikut adalah output hasil uji asumsi normalitas.

Tabel 4. Hasil Uji Asumsi Normalitas Univariat

\begin{tabular}{ccccc}
\hline \multirow{2}{*}{ Variabel } & \multicolumn{3}{c}{ Kolmogorov-Smirnov } & \multirow{2}{*}{ Ket } \\
\cline { 2 - 4 } & Stat & Df & Sig. & \\
\hline Berpikir Matematis & 0.773 & 68 & 0.589 & Normal \\
\hline
\end{tabular}

Berdasarkan Tabel 4 di atas, terlihat bahwa nilai signifikansinya lebih dari 0,05. Dengan demikian dapat disimpulkan bahwa data sudah berdistribusi normal. Selanjutnya akan dilakukan uji homogenitas untuk melihat hasil levene's test dengan menggunakan software SPSS 20.0. Setelah dilakukan uji homogenitas diperoleh data sebagai berikut.

Tabel 5. Hasil Uji Homogenitas Varians

\begin{tabular}{cccc}
\hline Variabel & F & Sig. & Keterangan \\
\hline Berpikir matematis & 0.030 & 0.863 & Homogen \\
\hline
\end{tabular}

Berdasarkan Tabel 5, dapat dilihat bahwa nilai signifikansi levene's test untuk variable berpikir matematis lebih dari 0,05 . Dengan demikian dapat disimpulkan bahwa pada taraf nyata 0,05 varians kedua kelas homogen.

\section{Keefektifan Pendekatan Problem Posing}

Analisis keefektifan pendekatan pembelajaran problem posing ditinjau dari kemampuan berpikir matematis siswa dilakukan dengan menggunakan one sample t-test. Dengan menggunakan bantuan program SPSS 20.0 for windows diperoleh $t_{\text {hitung }}=4,208$ dengan nilai signifikansi 0,000. Jadi dapat disimpulkan bahwa pembelajaran matematika dengan pendekatan problem posing efektif ditinjau dari kemampuan berpikir matematis siswa. Hasil penelitian ini 
sesuai dengan hasil penelitian Yuniati (2010) dan Kusnaeni dan Retnawati (2013). Dalam penelitian Yuniati disebutkan bahwa pembelajaran matematika dengan menggunakan pendekatan problem posing mengalami peningkatan pemahaman dan penalaran matematika lebih baik dari siswa yang mendapatkan pembelajaran konvensional. Begitu juga halnya dengan penelitian Kusnaeni dan Retnawati yang menybutkan bahwa penerapan pendekatan problem posing lebih efektif dari pendekatan konvensional ditinjau dari komunikasi matematis siswa.

Keefektifan pendekatan pembelajaran problem posing kemungkinan besar disebabkan karena karakteristik dari pendekatan pembelajaran ini yang menyediakan kesempatan belajar kepada siswa melaui pengajuan masalah. Lavy \& Shriki (2007: 129) mengatakan bahwa salah satu keunggulan yang dimiliki oleh pendekatan pembelajaran problem posing ini adalah memicu kemampuan berpikir beragam dan fleksibel, meningkatkan kemampuan pemecahan masalah, dan meningkatkan kemampuan bernalar dan refleksi. Selain itu, Silver (1997: 75) mengungkapkan bahwa problem posing dapat membantu siswa mengembangkan kemampuan berpikir.

\section{Kesimpulan}

Berdasarkan hasil analisis data dan pembahasan diperoleh $t_{\text {hitung }}=4,208$ dengan nilai signifikansi 0,000. Jadi dapat disimpulkan bahwa pembelajaran matematika dengan pendekatan problem posing efektif ditinjau dari kemampuan berpikir matematis siswa.

\section{Referensi}

Brown, S.I. \& Walter, M.I. (2005). The art ofproblem posing ( $3^{r d}$ ed). Mahwah, New Jersey London: LEA

Cai, J. (1998). An investigation of U.S. and Chinese student' mathemastical problem posing and problem solving. (versi elektronik). Diambil tanggal 02 Agustus 2020, dari http://www.emis.de.

Christou, C. et al. (2005). An empirical taxonomy of problem posing processes. ZDM 2005 Volume 37 (3).

Cobern, W.W. (1993). Contextual constructivism: The impact of culture on the learning and teaching of science. Dalam K.G. Tobin (Ed.), The practice of constructivism in science education (pp. 51-69). Hillsdale, NJ: Lawrence Erlbaum Associates.

Creswell, J. W. (2013). Research design: qualitative, quantitative, and mixed methods approaches ( $3^{\text {rd }}$ ed). (Terjemahan Ahmad Fawaid \& Khoirul Anam). Thousand Oaks: SAGE Publications. (Buku asli diterbitkan pada tahun 2009).

Dick, W., Carey, L., \& Carey, J. O. (2005). The systematic design of instruction (5 $5^{\text {th }}$ ed). Boston: Library of Conggress Cataloging. 
English, Lyn D. (1997). Promoting a problem posing classroom. Teaching children mathematics, November 1997.p.172-179.

Ernest, P. (1991). The philosophy of mathematics education. University of Exeter: Taylor and Francis Group.

Haylock, D., \& Thangata, F. (2007). Key concept in teaching primary mathematics. Thousand Oaks: SAGE Publication.

Herman Hudoyo (2001). Pengembangan kurikulum dan pembelajaran matematika. Malang: Universitas Negeri Malang.

Jacobsen, D. A., Eggen, P., \& Kauchak, D. (2009). Methods for teaching. (Terjemahan Ahmad Fawaid \& Khoirul Anam). Upper Saddle River, NJ: Pearson Education. (Buku asli diterbitkan tahun 2009).

Johnson, E. B. (2007). Contextual teaching and learning. (Terjemahan Ibnu Setiawan). Thousand Oaks: Corwin Press, Inc. (Buku asli diterbitkan tahun 2002).

Johnson, R.A. dan Wichern, D.W. (2007). Applied multivariate statistical analysis. Upper Saddle River, NJ: Pearson Education.

Jonassen, D. H. (2004). Learning to solve problems: An instructional design guide. San Fransisco, CA: John Wiley \& Sons.

Joyce, B., Weil, M., \& Calhoun, E. (2004). Models of teaching (7 $7^{\text {th }}$ ed). Boston, MA: Pearson Education.

Katagiri, S. (2007). Mathematical thinking and how to teach it. Diambil tanggal 10 November 2012, dari http://home.kku.ac.th/crme/APEC/PDF\%202004

Khalid, M. (2007). Incorporating mathematical thinking in addition and subtraction of fraction: Real issues and challenges. Diambil tanggal 10 November 2012 dari http://www.crme.kku.ac.th/APEC/PDF\%202007/Madihah\%20 Khalid.pdf

Kilpatrick, J., Hoyles, C., Skovsmose, O. (2005). Meaning in mathematics education. New York: Springer.

Lavy, I. \& Shriki, A. (2007). Problem posing as a means for developing mathematical knowledge of prospective teachers. Makalah disajikan pada Proceedings of the $31^{\text {th }}$ Conference of The International Group for the Psychology of Mathematics Education, di Oranim Academic College of Education

Lewis, C.C. (2011). Building Japanese-Style Structured Problem-Solving Outside Japan: What Supportsare Needed?, APEC- Ubon Ratchathani International Symposium 
Maaß, J., \& Schlöglmann, W. (2009). Beliefs and attitudes in mathematics education. Rotterdam/Taipe: Sense Publisher

Marsigit. (2003). Pembelajaran matematika berdasarkan kurikulum berbasis kompetensi di SMK. Disampaikan pada penataran kurikulum matematika berbasis kompetensi untuk SMK di BPG Yogyakarta.

Marsigit. (2007, November). Mathematical thinking across multilateral culture. Makalah disajikan dalam Seminar Nasional Pembelajaran Matematika Sekolah, di Universitas Negeri Yogyakarta

Marsigit. (2009, Desember). Pembudayaan matematika di sekolah untuk mencapai keunggulan bangsa. Makalah disajikan dalam Seminar Nasional Pembelajaran Matematika Sekolah, di Universitas Negeri Yogyakarta.

Marsigit. (2011, Juli). Developing the attitude and creativity in mathematics education. Makalah disaiikan dalam The International and The Fourth National Conference on Mathematics, di Universitas Negeri Yogyakarta.

Maton, K., \& Moore, R. (2010). Social realism, knowledge and the sociology of education: coalitions of the mind. New York: Continuum.

Mendiknas. (2006). Peraturan Menteri Pendidikan Nasional nomor 22, Tabun 2006, tentang Standar Isi.

Moore, K. D. (2014). Effective instructioal strategies: from theory to practice. Thousand Oaks: Sage publication, Inc.

Muijs, D. \& Reynolds, D. (2008). Effective teaching. (Terjemahan Helly Prajitno Soetjipto \& Sri Mulyantini Soetjipto). London: Sage Publications. (Buku asli diterbitkan tahun 2005).

Mulyasa. (2009). Standar kompetensi dan sertifikasi Guru. (Cetakan keempat). Bandung: PT Remaja Rosda Karya

NCTM. (2000). Principles and standars for school mathematics. New York: The National Council of Teachers of Mathematics, Inc.

Nitko, A. J. \& Brookhart, S. M. (2007). Educational assesment of students. Upper Saddle River, NJ: Pearson Education.

OECD (2014). Pisa 2012 result: what students know and can do- students performance in reading, mathematics, and science (volume 1). Corrigenda: Clearance Center.

Orlich, D. C., Harder, R. J., Callahan, R. C., Trevisan, M. S., et al. (2007). Teaching Strategies - a guide to effective instruction ( $8^{\text {th }}$ ed). New York: Houghton Mifflin Company.

Orton, A. (2004). Learning Mathematics: Issues, theory and classroom practice ( $3^{\text {rd }}$ ed). London. New York: Continuum. 
Paul Suparno. (1997). Filsafat konstruktivisme dalam pendidikan. Yogyakarta: Kanisius.

Paul Suparno, Rohandi, Sukadi, Kartono. (2002). Reformasi pendidikan, sebuah rekomendasi. Yogyakarta: Kanisius.

Polya, G. (1981). Mathematical discovery. On understanding, learning, and teachning problem solving. New York: John Wiley \& Sons.

Posamentier, A. S., \& Stepelmen, J. (1990). Teaching secondary school mathematics: Techniques and enrichment units $\left(3^{\text {rd }}\right.$ ed.). Columbus, Ohio: Merrill Publishing Company.

Posamentier, A. S., Smith, B. S., \& Stepelmen, J. (2010). Teaching secondary school mathematics: Techniques and enrichment units ( $8^{\text {th }}$ ed.). New York: Pearson Education, Inc.

Presiden. (2005). Peranturan Pemerintah no 19, Tabun 2005, tentang Standar Nasional Pendidikan.

Presiden. (2007). Peranturan Pemerintah no 41, Tabun 2007, tentang Standar Proses.

Pritchard, A \& Woolard, J. (2010). Psychology for the classroom: Contructivisme and Social Learning. New York : Madison Avenue.

Republik Indonesia. (2003). Undang-Undang RI nomor 20, Tabun 2003, tentang Sistem Pendidikan Nasional.

Romberg, T. A., \& Kaput, J. J. (2009). Mathematics worth teaching, mathematics worth understand. Dalam E. Fennema \& T.A. Romberg (Eds.) mathematics classroom that promote understanding (pp.3-18). Mahwah, NJ: Taylor \& Francis e-Library.

Saifuddin Azwar. (2012). Metode penelitian. Yogyakarta: Pustaka Pelajar.

Silver, E.A. (1996). Posing mathematical problems: an exploratory study. Journal for research in mathematics education, pp 292-309

Silver, E.A. (1997). Fostering creativity through instruction rich in mathematics problem solving and problem posing. Diambil pada tanggal 2 Agustus 2012, dari http:/www.emis.de

Slavin, R. E. (2011). Educational psychology: theory and practice, $\left(9^{\text {th }}\right.$ ed). (terjemahan Marianto Samosir). Boston: Pearson Education, Inc. (Buku asli diterbitkan tahun 2006).

Soedjadi, R. (2000). Kiat pendidikan matematika di Indonesia. Konstatasi keadaan masa kini menuju harapan masa depan. Depdiknas.

Stacey, K. (2007). What is mathematical thinking and why is it important?. Center for Research on International in Educational Development. University of Tsukuba.

Steven, J. P. (2009). Applied multivariate statistics for the social sciences $\left(5^{\text {th }}\right.$ ed). New York \& London: Routledge Taylor \& Francis Group.

Ahmad Nasrullah (2021), The Effectiveness of Problem Posing Approach..... 
Suryosubroto. (2009). Proses belajar mengajar di sekolah. Jakarta: Rineka Cipta.

van de Walle (2008). Sekolah dasar dan menengah: pengembangan pembelajaran. (Terjemahan Suyono). Upper Saddle River, New Jersey: Pearson Education, Inc. (Buku asli diterbitkan tahun 2004).

Wina Sanjaya. (2011). Strategi pembelajaran berorientasi standar proses. Jakarta: Prenada Media.

Xia Xiogang, Chuanhan Lu, \& Bingyi Wang. (2008). Research on mathematics instruction experiment based problem posing. Journal of mathematics education December 2008, vol 1 No 1, pp. 153-163. Guizhou Normal University, China.

Yuniati, S. (2010). Meningkatkan kemampuan pemahaman dan penalaran matematik siswa sekolah menengah pertama dengan pembelajaran problem posing. Tesis magister, tidak diterbitkan, Universitas Pendidikan Indonesia, Bandung. 